\title{
Interpretation of Mandibular Condyle Fractures Using 2D- and 3D-Computed Tomography
}

\author{
Adriana Paula de Andrade da COSTA E SILVA ${ }^{1,3}$ \\ José Leopoldo Ferreira ANTUNES ${ }^{2}$ \\ Marcelo Gusmão Paraiso CAVALCANTI ${ }^{1,4}$ \\ ${ }^{1}$ Department of Oral and Maxillofacial Radiology \\ ${ }^{2}$ Department of Social Science \\ Faculty of Dentistry, University of São Paulo, São Paulo, SP, Brazil \\ ${ }^{3}$ Department of Legal Odontology, Faculty of Dentistry, Federal University of Pernambuco, PE, Brazil \\ ${ }^{4}$ Department of Radiology, College of Medicine, University of Iowa, Iowa City, IO, USA
}

\begin{abstract}
Computed tomography (CT) has been increasingly used in the examination of patients with craniofacial trauma. This technique is useful in the examination of the temporomandibular joint and allows the diagnosis of fractures of the mandibular condyle. Aiming to verify whether the three-dimensional reconstructed images from CT (3D-CT) produce more effective visual information than the twodimensional (2D-CT) ones, we evaluated 2D-CT and 3D-CT examinations of 18 patients with mandibular condyle fractures. We observed that 2D-CT and 3D-CT reconstructed images produced similar information for the diagnosis of fractures of the mandibular condyle, although the 3D-CT allowed a better visualization of the position and displacement of bone fragments, as well as the comminution of fractures. These results, together with the possibility of refining and manipulating perspectives in 3D images, reinforce the importance of its use in the surgical planning and evaluation of treatment. We concluded that 3D-CT presented supplementary information for a more effective diagnosis of mandibular condyle fractures.
\end{abstract}

Key Words: tomography, x-ray computed tomography, image processing, mandibular condyle, fractures.

\section{INTRODUCTION}

The diagnosis of fractures of the mandibular condyle is performed by clinical and radiographic examinations. Clinical signs, such as bone deflection, difficulty in opening the mouth, malocclusion, and edema in the peripheral region of the auricle may be indicative of traumatic uni- or bilateral fractures of the mandibular condyle (1).

Conventional radiographs are routinely used for the examination of this site. However, the overlap of structures may impair a proper interpretation of images (2). Intra-capsular fractures of the mandibular condyle and fractures in the high portion of its condylar process are difficult to see in plain films. Contingent on the position, the image may miss the displacement of bone fragments, impairing a correct diagnosis.

Since the 1980s, computed tomography (CT) has been extensively used in patients affected by trauma. The posterior introduction of spiral CT allows the visualization of cross-sectional images, which improves the diagnosis of fractures by suppressing the undesired visual overlap of sections, distinguishing soft tissues and bone structures, facilitating the anatomic localization of the lesions. Several studies reported the interpretation of 3D-CT images as supplying more information than $2 \mathrm{D}-\mathrm{CT}$, and therefore providing more reliable diagnoses and effective therapeutics, which improves the prognosis of patients, and reduces the manifestation of sequelae (3-8).

3D-CT has been applied in the diagnosis, therapeutic planning and follow-up of maxillofacial surgeries. Mainly, this method is useful in the assessment of facial asymmetries and bone displacements. Bianchi et al. (9) reported several condylar fractures in which 3D-CT contributed to the surgical reconstitution of affected

Correspondence: Dr. Marcelo Cavalcanti, Departamento de Radiologia, Faculdade de Odontologia, Universidade de São Paulo, Av. Prof. Lineu Prestes 2227, 05508-900 São Paulo, SP, Brasil. Tel: +55-11-3818-7807. Fax: +55-11-3818-7831. e-mail: mgpcaval@usp.br 
structures and the removal of bone fragments.

When associated with computer graphics systems in a workstation, 3D-CT produced relevant improvements in the diagnosis of fractures of the maxillofacial complex (10). Also 3D-CT allowed a real impression of the anatomic condition of tegument and bone structures (11).

The current study evaluated the effectiveness and incremented information of the imaging findings from 3D-CT compared to 2D-CT in the diagnosis of mandibular condyle fractures.

\section{MATERIAL AND METHODS}

We evaluated 18 patients with facial trauma and fracture of the mandibular condyle, who were submitted to a spiral CT (Toshiba S/X Press, Toshiba Medical System, Tustin, CA), with the following parameters: 2 $\mathrm{mm}$ of slice thickness, $2 \mathrm{~mm}$ of table feed by $1 \mathrm{~mm}$ of reconstruction interval in 1 second time, using 120 $\mathrm{KVp}$ and $150 \mathrm{~mA}$, and Matrix 512 X 512.

Two specially trained and calibrated examiners performed independently the examinations in 2D-CT and 3D-CT in a random order. The surgical observation was the gold standard corroborating the diagnosis of the condylar fracture, its anatomic localization (head, neck or condylar process), the occurrence of comminution, and medial, lateral or anterior displacement of bone structures. We have not appraised information regarding the gender and age of patients, nor the cause of the lesions.

The validity assessment of a diagnostic tool refers to its ability in distinguishing between who has some characteristic and who does not (12). Sensitivity refers to the ability of correctly identifying those who

Table 1. Validity assessment (sensitivity and specificity) of the diagnosis by the 2D-CT and 3D-CT techniques compared to the surgical observation.

\begin{tabular}{lccccc}
\hline & \multicolumn{2}{c}{$2 \mathrm{D}-\mathrm{CT}$} & & \multicolumn{2}{c}{ 3D-CT } \\
\cline { 2 - 3 } \cline { 5 - 6 } \cline { 5 - 6 } & Sensitivity & Specificity & & Sensitivity & Specificity \\
\hline Fracture & & & & \\
Comminution & $3 / 4(75 \%)$ & $13 / 14(93 \%)$ & & $4 / 4(100 \%)$ & $14 / 14(100 \%)$ \\
Anatomic localization & $18 / 18(100 \%)$ & $17 / 18(94 \%)$ & & $18 / 18(100 \%)$ & $18 / 18(100 \%)$ \\
Medial displacement & $3 / 7(42.8 \%)$ & $7 / 7(100 \%)$ & & $7 / 7(100 \%)$ & $7 / 7(100 \%)$ \\
Lateral displacement & $2 / 4(50 \%)$ & $4 / 4(100 \%)$ & & $3 / 4(75 \%)$ & $4 / 4(100 \%)$ \\
Anterior displacement & $8 / 10(80 \%)$ & $10 / 10(100 \%)$ & & $9 / 10(90 \%)$ & $10 / 10(100 \%)$ \\
\hline
\end{tabular}

have the disorder. Therefore, we considered whether the examined techniques correctly identified different conditions: the presence of fractures, localization, comminution and bone displacement. Specificity is the ability of correctly identifying who do not have the disorder. Therefore, we considered whether the examined techniques correctly identified the absence of those conditions.

The original data were transferred to an independent workstation (Dell Precision hardware, Windows NT 420), with the software Vitrea ${ }^{\circledR}$ version 2.1 (Vital Images Inc., Plymouth, MN) to generate an automatic and simultaneous $3 \mathrm{D}$ volume rendering reconstructed images by using DICOM 3.0 (Digital Imaging and Communication in Medicine; Toshiba). Then the images were processed, manipulated, and interpreted in the workstation using the 3D software tools, which also allowed segmentation of the region of interest, and "fly through" techniques. The statistical analyses were carried out using the validity test of SPSS software (Chicago, IL) to assess the sensitivity and specificity of imaging modalities.

\section{RESULTS}

The surgical examination confirmed the presence of condylar fractures in all patients. Four of them also presented comminution, 7 presented medial bone displacement, 4 presented lateral bone displacement, and 10 presented anterior bone displacement, while 8 patients did not present bone displacement.

Assessment of sensitivity and specificity of the 2D-CT and 3D-CT techniques is reported in Table 1. Both resources were sensitive and specific for the diagnosis of condylar fractures, with a mild advantage of 3D-CT to the anatomic localization of the lesions. The monitoring of different segments and positions by $3 \mathrm{D}-\mathrm{CT}$ increased the validity of this technique, by allowing better visualization of these images. The manipulation of 3D images by the Vitrea software, permitted refining the visualization by using computer graphics tools. Thus, images generated by the 3D-CT volume technique could be rotated, trans- 
ported, approximated or even have a transparency device inserted, in order to improve the visualization and consequently the interpretation of the cases.

Figures 1 and 2 represent the difference of visualization between these techniques. Figure 1A shows 2D-CT (axial slice) imaging of bilateral condylar fractures, which on the left side demonstrated a mild anterior bone displacement. In both sides, the medial or lateral displacement could not be observed.

The 3D-CT imaging showed the medial and anterior bone displacement of bilateral condylar fractures (Figure 1B-D). For that, the articular fossa was better observed in this imaging modality. The manipulation of 3D images by the Vitrea software permitted a better visualization of the condylar fracture and of the bone displacement after its segmentation from the whole adjacent anatomical structures (Figure 1E,F).

In case 2, we visualized the condylar fracture in the right side (Figure 2A) from 2D-CT. This image permitted only the visualization of anterior bone displacement of the condylar fracture. When the 3D-CT technique was used, we observed the anterior and medial bone displacement of the condylar fracture (Figure 2B-D). In this case, the images were refined to improve the visualization of the fracture.

\section{DISCUSSION}

The usefulness of CT has significantly improved diagnoses by images (13). Several studies confirm that CT supplies relevant information for the diagnosis, therapeutic planning and surgical follow-up of patients with facial trauma $(8,10,14-16)$.

Raustia et al. (1) reported dysfunction of the temporomandibular joint as the target of the first protocol addressing the dental use of CT. They also stated the advantages of this method for examinations of the mandibular condyle because of its ability of simultaneously highlighting modifications of tegument and bone structures. The monitoring of CT images allow the visualization of different sections of the mandibular condyle, identifying its relation with the articular fossa, as well as medial, lateral or anterior bone displacement of fractures. Raustia et al. (1) also affirmed that 2D-CT axial sections are a relevant contribution for the diagnosis of the anatomic position and motion restriction of the mandibular condyle. 2D-CT coronal section improves the evaluation of medial and lateral displacements of the mandibular condyle in the articular fossa. This section also allows the visualization of the upper and medial portions of the mandibular condyle and the articular fossa.

Laskin (6) pointed out the degree and the direction of bone displacement in condylar fractures as influenced by several factors, such as the direction of the traumatic force, the position of the mandible during impact, the influence of the lateral pterygoid muscle, and the presence of other fractures in the mandible or in the articular fossa. Bone displacements are more frequent in the medial and anterior directions, but other directions are also possible.

The present study evaluated 2D-CT and 3D-CT imaging as effective techniques for the diagnosis of condylar fractures. From the 13 patients presenting surgical confirmation of bone displacement, only 5 patients had this condition visualized by $2 \mathrm{D}$ images, while 11 presented evidence by the 3D technique. This indicated the increment of visual information to the diagnosis of this condition.

Bianchi et al. (9) described difficulties associated with the use of 2D-CT images from axial and coronal slices for the diagnosis of condylar fractures. A direct image from a coronal slice may be difficult to achieve by using this technique, and the coronal reconstruction by using axial images may be deficient. Furthermore, the 2D-CT would also present limitations to the visualization of the border of the mandibular condyle, the localization of bone fragments, and the direction of bone displacement. These difficulties led the authors to produce reconstructions of these images, which, however, were considered insufficient because they proceeded from a conventional computed tomograph, without an independent workstation.

In the present study, we interpreted the images using a spiral CT in an independent workstation. Thus, we could improve the validity of the 2D-CT examinations, failing in the interpretation of the anatomic localization of the condylar fracture in only one case, while the 3D-CT presented maximum sensitivity and specificity in the diagnosis of this condition (Table 1). With respect to comminution of the condylar fracture (Figure 1), the 2D-CT technique presented one false negative and one false positive, while the 3D-CT presented none.

According to Ohkawa et al. (17), both 2D-CT and 3D-CT techniques have similar sensitivity for the 

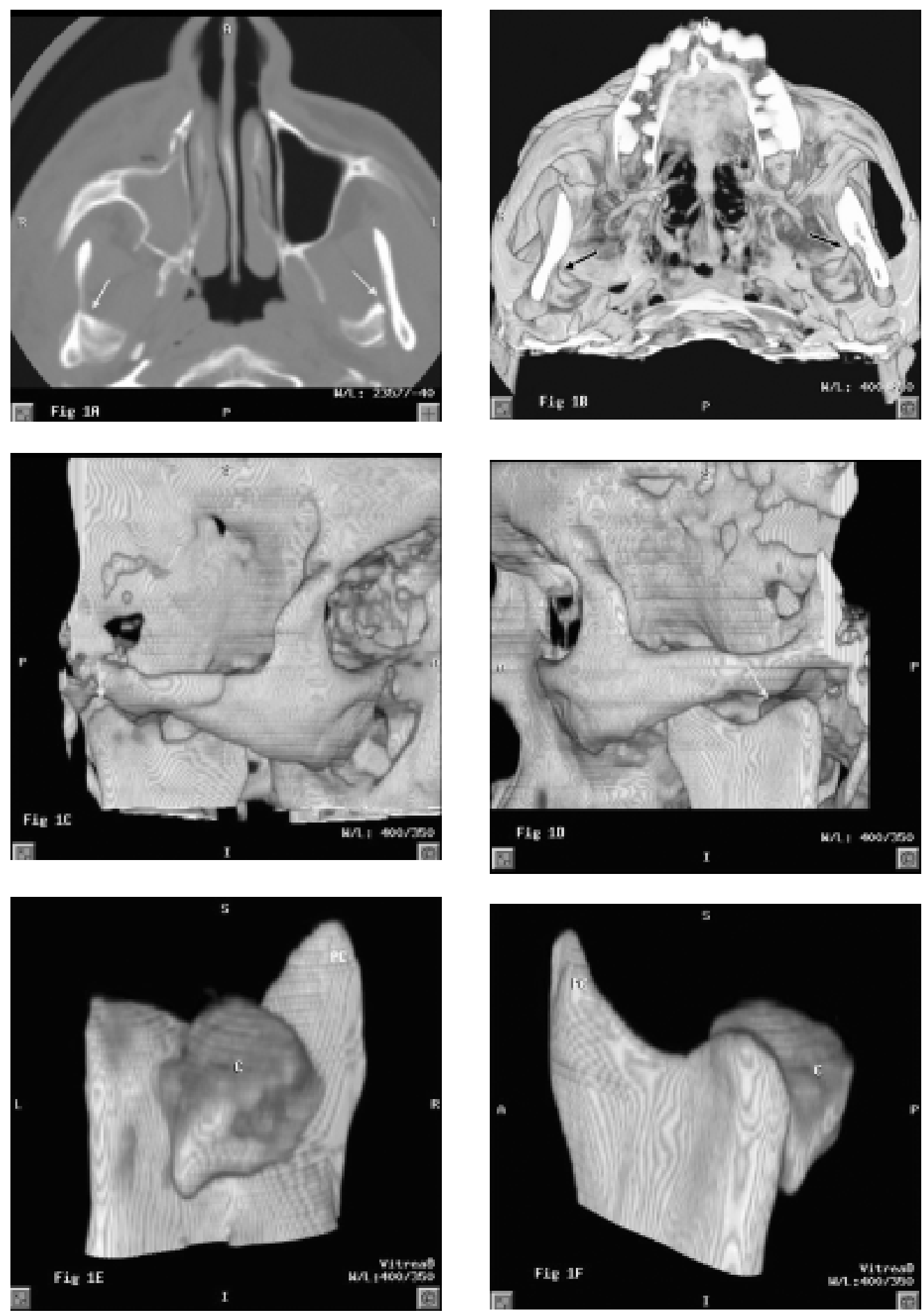

Figura 1. Panel A: 2D-CT axial slice shows the bilateral condylar fractures, demonstrating a mild anterior bone displacement on the left side (arrows). Panel B: 3D-CT axial view demonstrates a more realistic direction of bilateral condylar fractures, improving visualization of the direction of the displacement and the anatomical relationship (arrows). Panels C and D: 3D-CT lateral views are depicting the right and left condylar fractures, respectively. In the right side, the fracture occurs in the head of the condyle while the left side presents lower fracture in the neck of the condyle (arrows). Panels E and F: 3D-CT after the imaging segmentation of the displaced condyle shows its relationship to the fracture portion of the mandible by computer graphics software. These figures also show the anterior bone displacement of the left condylar fracture $(\mathrm{C}) . \mathrm{PC}=$ coronoid process. 
diagnosis of fractures in the mandibular region. However, they also reported that the 3D-CT image allowed a better visualization. Carls et al. (18) and Rhea et al. (19) also observed that 3D images provide better identification and easier detection of specific characteristics of facial and cranial asymmetries, defects in the medial portion of the face and in the skull vault, and fractures associated with extensive bone displacement, which may affect different cranial sections. The present study, in which, in spite of the verification of 2D-CT and 3DCT as similarly valid in the diagnosis of condylar fractures, the latter provided an improved examination of affected structures, is in agreement with these authors. The thickness of the sections, table feed, and reconstruction interval are some of the elements of a proper 3D-CT protocol, whose application permitted a better visualization of condylar fractures than 2D-CT images, from different angles, and a higher sensitivity when compared to the surgical observation (20).

These images also permitted an overall visualization of the mandibular condyle, bone displacements and comminution of fractures. However, there are also restrictions to the use of 3D-CT images (13), which should not substitute, but should complement the 2DCT technique. This observation accounts for the importance of further studies assessing the validity of 3D-CT images, before their widespread use can be adopted.

When performed under a proper protocol, both 2D-CT and 3D-CT presented similar validity in the diagnosis of condylar fractures. However, the 3D-CT technique produced images that allowed an improve-
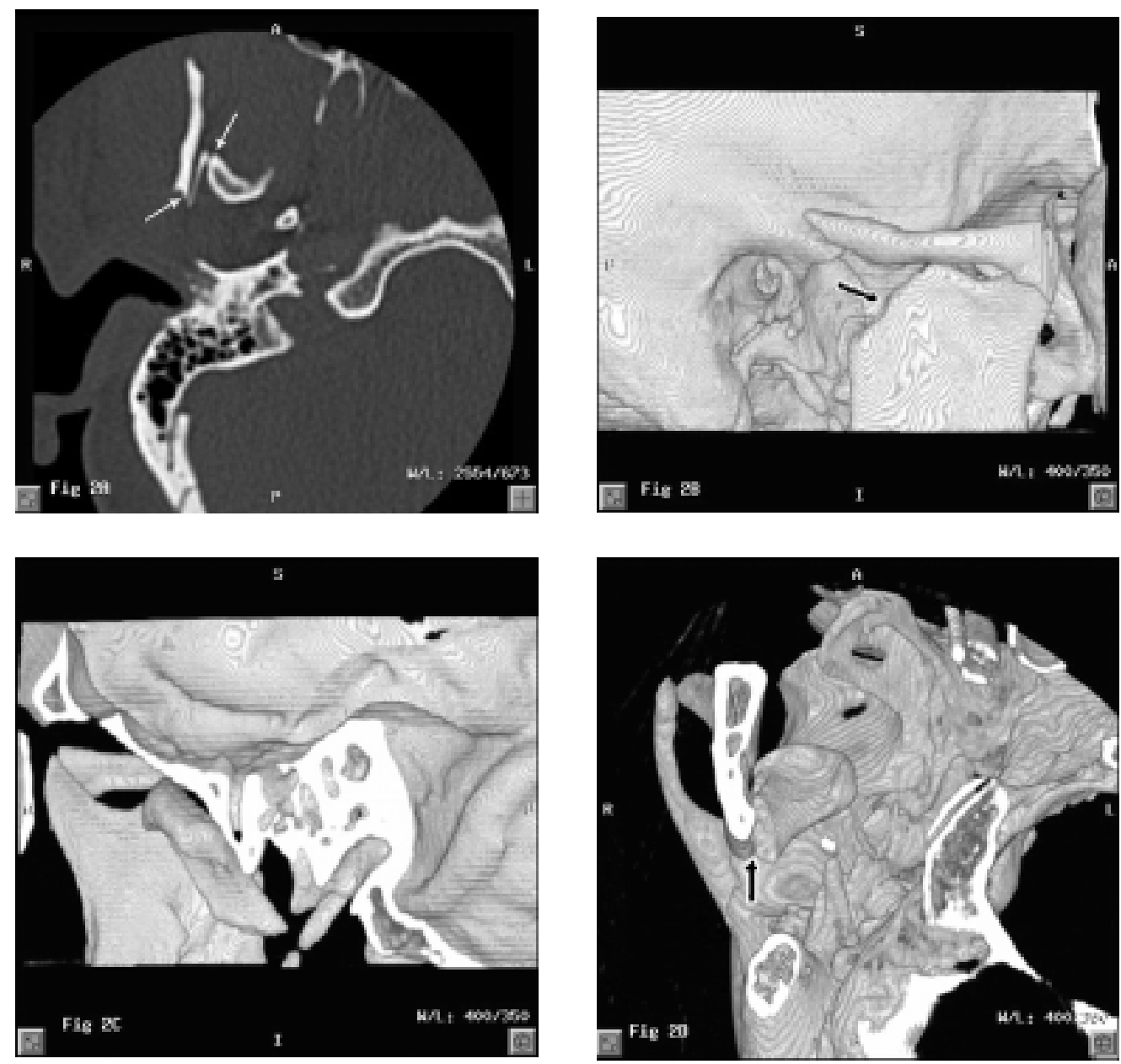

Figura 2. Panel A: 2D-CT axial view shows the condylar fracture in the right side and anterior displacement (arrows). Panel B: 3D-CT presents lateral view of the condylar fracture (arrows), showing that the fracture occurred in the condylar process. Panels C and D: 3D$\mathrm{CT}$ indicates the position of the condylar fracture from the inner and infero-superior views, respectively. 
ment in the visualization of affected structures, which provided higher indicators of specificity in the identification of the anatomic localization of the fracture, and sensitivity in detecting comminution and bone displacement. Therefore, the present study reinforces the effectiveness of the 3D-CT technique as a supplementary procedure to the $2 \mathrm{D}-\mathrm{CT}$ in the examination of the maxillofacial complex.

\section{ACKNOWLEDGEMENTS}

This study was supported by FAPESP (São Paulo, Brazil; grant: 99/10276-4; Prof. Dr. M.G.P. Cavalcanti), and by CAPES (Brasília, Brazil; PhD scholarship; Dr. A.P.A. da Costa e Silva).

\section{RESUMO}

A tomografia computadorizada (TC) tem sido cada vez mais utilizada para exames de pacientes portadores de traumas craniofaciais. Essa técnica tem apresentado vantagens no exame da articulação temporomandibular, sendo também empregada com sucesso no diagnóstico de fraturas de côndilo. Com o propósito de verificar se a reconstrução em 3 dimensões de imagens de TC (3D-TC) acrescenta informação visual às interpretações baseadas em imagens de 2D-TC, o presente trabalho avaliou qualitativamente exames realizados segundo ambas as técnicas em 18 pacientes portadores de fraturas por trauma do côndilo mandibular. Os resultados indicaram que a $2 \mathrm{D}-\mathrm{TC}$ e a 3D-TC apresentaram informações similares para o diagnóstico dessas fraturas. Contudo, as imagens reconstruídas em 3D-TC forneceram indicações mais precisas quanto à posição anatômica da fratura, deslocamento dos fragmentos ósseos e presença de cominução nas fraturas. Estes resultados, aliados à possibilidade de refinamento e manipulação em vários ângulos das imagens em $3 \mathrm{D}$, sublinham sua aplicabilidade no planejamento e acompanhamento cirúrgico daquelas fraturas. Concluiu-se que a técnica de 3D-CT apresentou informações suplementares para um diagnóstico mais preciso das fraturas de côndilo mandibular.

\section{REFERENCES}

1. Raustia AM, Pyhtinen J, Olkarinen KS, Altonen M. Conventional radiographic and computed tomographic findings in cases of fracture of the mandibular condylar process. J Oral Maxillofac Surg 1990;48:1258-1264

2. Gonçalves N. Aspectos radiográficos da articulação temporomandibular. In: Radiologia Odontológica. Freitas A, Rosa JE, Souza IF. eds. $5^{\text {th }}$ edn. São Paulo: Artes Médicas; 2000. p. 227-
234.

3. Altobelli DE, Kikinis R, Mulliken JB, Cline H, Lorense W, Jolesz F. Computer-assisted three-dimensional planning in craniofacial surgery. Plast Reconst Surg 1993;92:576-585.

4. Cavalcanti MGP, Haller JW, Vannier MW. Three-dimensional computed tomography landmark measurement in craniofacial surgical planning: experimental validation in vitro. J Oral Maxillofac Surg 1999;57:690-694.

5. Cavalcanti MGP. Tomografia computadorizada: Reconstruções em 2D e em 3D. In: Radiologia Odontológica. Freitas A, Rosa JE, Souza IF. eds. $5^{\text {th }}$ edn. São Paulo: Artes Médicas; 2000. p. 681725.

6. Laskin MD. Diagnosis of pathology of the temporomanibular joint. Clinical and imaging perspectives. Radiol Clin N Am 1993;31:135-147.

7. Manson PN, Markowitz B, Mirvis S, Dunham M, Yaremchuk M. Toward CT-based facial fracture treatment. Plast Reconst Surg 1990;85:202-212.

8. Novelline RA, Rhea JT, Rao PM, Stuk JL. Helical CT in emergency radiology. Radiol 1999;213:321-339.

9. Bianchi SD, Lojacono AJ, Gioanni PP, Spada MC, Ramieri G. 3-D $\mathrm{CT}$ investigation of mandibular condyle fractures. IADMFR/ CMI'97 - Advances in Maxillofacial Imaging 1997;143-149.

10. Costa e Silva APA, Panella J, Cavalcanti MPG. Análise da sensibilidade da 3D-TC para o diagnóstico de fraturas faciais. Rev Pós-grad FOUSP 2001;8:273.

11. Falk A, Gielen S, Heuser L. CT data acquisition as a basis for modern diagnosis and therapy in maxillofacial surgery. Int J Oral Maxillofac Surg 1995;24:69-75.

12. Szklo M, Javier-Nieto F. Epidemiology: beyond the basics. Gaithersburg, MD: Aspen, 2000.

13. Albrecht T, Blomley MJK. Spiral computed tomograph: principles and clinical use. Hospital Medicine 1998;59:121-125.

14. Druelinger L, Guenther M, Marchand G. Radiographic evaluation of the facial complex. Emerg Med Clin N Am 2000;18:393410.

15. Nortjé CJ. Traumatic injuries In: Oral and Maxillofacial Diagnostic Imaging. Farman AG, Nortjé CJ, Wood RE. eds. 1st edn. Mosby: St Louis. 1993. p. 158-180

16. Yang J, Cavalcanti MGP, Ruprecht A, Vannier MW. 2-D and 3D reconstructions of spiral computed tomography in localization of the inferior alveolar canal for dental implants. Oral Surg Oral Med Oral Pathol Oral Radiol Endod 1999;87:369-374.

17. Ohkawa M, Tanabe M, Toyama Y, Kimura N, Uematsu K, Satoh $\mathrm{G}$. The role of three-dimensional computed tomography in the management of maxillofacial bone fractures. Acta Med Okayama 1997;51:219-225.

18. Carls FR, Schuknecht B, Sailer HF. Value of three-dimensional computed tomography in craniomaxillofacial surgery. Cranio 1994;5:282-288

19. Rhea JT, Rao PM, Novelline RA. Helical CT and three-dimensional CT of facial and orbital injury. Radiol Clin N Am 1999;37:489-513.

20. Zinreich SJ, Mattox DE, Johns ME, Holliday MJ, Kashima HK, Kennedy DW, Price JC, Quinn CB. 3-D CT for cranial, facial and laryngeal surgery. Laryngoscope 1988;98:1212-1219.

Accepted September 30, 2002 